\title{
Diabetes Melito Tipo 1: da Pesquisa à Clínica
}

E NTRE A PRIMEIRA DESCRIÇÃO DE DIABETES, no papiro de Eber (Egito, 1552 U.C.), como "poliúria indolor e emagrecimento", e a última publicação da Associação Americana de Diabetes (ADA) (1) sobre a classificação de diabetes, que relatou aproximadamente 57 etiologias diferentes para essa doença, houve uma longa caminhada, que revisaremos brevemente.

Há 70 anos, Dupertius, um antropologista de Nova York (EUA), classificando portadores de diabetes pelo fenótipo, usou pela primeira vez os termos diabetes melito tipo $1(\mathrm{DM} 1)$ e tipo 2 (DM2), identificando que os primeiros eram acentuadamente mais magros e mais jovens do que os do grupo 2 (2).

A caracterização do DMl como diabetes insulinopênico começou na década de 1950 pela observação de que o pâncreas de jovens $(<20$ anos) com diabetes tinham $40 \%$ a $50 \%$ menos insulina do que os dos indivíduos normais (3) e as evidências de que esta glândula era alvo de processos inflamatórios $(4,5)$. A caracterização precisa da insulite, no entanto, só ocorreu na década de 1960, quando Gepts descreveu esse quadro histológico em pâncreas de jovens com diabetes que faleceram dentro dos seis primeiros meses do diagnóstico (6). A base da etiologia auto-imune para esse processo que culmina no DMl começou com a descrição por Ungar e col. (7) ainda na década de 1960 de anticorpos antitireoidianos e de antimucosa gástrica nos pacientes que eram portadores de insulite. Essa hipótese era reforçada por comentários de Irvine e col. (8) e por estudos de Nerup demonstrando que a prevalência de doença de Addison e de anticorpos antiadrenais estava aumentada nos pacientes com DMl. Como também o contrário era verdadeiro, maior prevalência de DMl era encontrada nos indivíduos com adrenalite (9). Essas considerações vieram a ser consolidadas pela caracterização dos anticorpos antiilhotas, em 1974, por Bottazzo e col. (10) em um grupo de pacientes com poliendocrinopatias, com ou sem diabetes. Dois anos após, Cudworth deu um passo importante na classificação etiológica do diabetes reintroduzindo os termos de diabetes tipo 1 e tipo 2 (11). Esse autor afirmava que o DMl, embora ocorresse principalmente nos jovens, poderia surgir em qualquer idade e se caracterizava por início abrupto e dependência de insulina.

Atualmente, o DMl é considerado o resultado de um processo auto-imune específico contra as células-beta pancreáticas, mediado pelos linfócitos $\mathrm{T}(12)$.

O DMl é uma das doenças mais estudadas dentro da medicina interna. Os avanços na complexidade de sua patogênese, seu diagnóstico, seu tratamento e suas complicações são encontrados em aproximadamente 47 mil trabalhos disponíveis no PubMed (fevereiro, 2008).

A incidência de DMl é altamente variável, podendo ir de 0,1/1.000.000/ ano em uma região do interior da China a mais de 40/100.000/ano na Finlândia (13).

Entretanto, a incidência dessa doença parece estar aumentando em todas as populações e, já nos próximos dois anos, deverá ser $40 \%$ superior à do ano editorial

\section{Sergio Atala Dib \\ BALDUINO TSCHIEDEL \\ MARCIA NerY}

Professor-associado, Livre-docente da Disciplina de Endocrinologia, Coordenador do Centro de Diabetes da

Universidade Federal de São Paulo, SP, Brasil (SAD);

Médico endocrinologista, mestre em Genética, Diretor do Instituto da Criança com Diabetes do Hospital da Criança Conceição, Porto Alegre, RS, Brasil (BT);

Médica-assistente doutora da Disciplina de Endocrinologia e chefe do Setor de Diabetes do Hospital da Clínicas da Faculdade de Medicina da Universidade de São Paulo, SP Brasil (MN). 
de 1997 (14), com aumento maior (6,3\%) entre crianças de 0 a 4 anos (15).

A grande disparidade na incidência do DMl entre os diferentes grupos étnicos provavelmente está relacionada aos fatores genéticos e ambientais.

O DMl auto-imune (DMlA) tem-se tornado uma das doenças poligênicas mais estudadas. À medida que evolui o estudo do genoma humano, vários genes têm sido implicados à suscetibilidade dessa doença. Além das fortíssimas associações tanto com a suscetibilidade quanto com a proteção para a doença (esses genes são responsáveis por aproximadamente $45 \%$ de sua suscetibilidade genética) com determinadas moléculas do HLA DR e DQ, outros genes, tais como CTLA4 (cytotoxic T-lymphocyte-associated protein 4), IFIHI (interferon induced with helicase C domain 1), ITPR3 (inositol 1,4,5-triphosphate receptor 3), receptor da IL-2 e PTPN22 (protein tyrosine phosphatase, nonreceptor type 22), têm sido implicados à predisposição genética do DMlA.

Apesar de raros, devemos lembrar-nos também dos casos de DMIA como componentes das síndromes IPEX (immune dysregulation, polyendocrinopthay, enteropathy, $X$-linked) e SPAI-I (autoimmune polyendocrine syndrome type 1) relacionadas às mutações nos genes FoxP3 (forkhead box P3) e AIRE (autoimmune regulator), respectivamente, conhecidos como DMlA "monogênicos".

Os recentes avanços tecnológicos na identificação de genes e a formação de grupos de estudo cooperativos deverão aumentar a velocidade da descoberta de novos genes para o DMlA.

Todos os fatores genéticos conhecidos, até o momento, podem ser responsáveis por no máximo $65 \%$ a $70 \%$ dos casos de DMlA e não explicam o aumento de sua incidência nas últimas décadas. Esses dados sugerem a importância de fatores ambientais no processo patogênico da doença. Uma das principais hipóteses, nesse sentido, é a chamada "hipótese higiênica", na qual o aumento na incidência da doença está relacionado ao baixo índice de infecções durante a infância (16). Os fatores ambientais mais especificamente implicados são a dieta (leite bovino, cereais e deficiência de vitamina D ou de ácidos graxos ligados ao ômega-3) e viroses (enteroviroses). O sedentarismo e a obesidade, cuja incidência vem crescendo, são fatores que também podemos chamar de ambientais, e possibilitam a ocorrência simultânea, em alguns pacientes, de resistência à insulina e também de auto-imunidade antiilhotas, denominados por alguns autores "diabetes duplo" (17). Por isso não existe motivo para negarmos a coexistência do diabetes tipo 2 e tipo $1 \mathrm{~A}$ no mesmo indivíduo.

Outro grupo de pacientes que tem chamado a atenção são as crianças ou os jovens inicialmente classificados como tipo 1 , mas que não apresentam autoanticorpos antiilhotas, especialmente quando medidos ao diagnóstico, permanecendo com função residual de células-beta [peptídeo-C de jejum $>0,2 \mathrm{pmol} / \mathrm{mL}(0,6$ $\mathrm{ng} / \mathrm{mL}$ )] após três anos de doença, antecedente familiar fortemente positivo e alguns com diagnóstico antes dos 6 meses de idade (18). Esses indivíduos são candidatos a uma investigação de mutações em determinados genes (MODY- maturity onset diabetes of the Young-, desordens mitocondriais e do Kir 6.2 entre outras), o que poderá sugerir mudanças em sua terapêutica.

Os objetivos do tratamento dos jovens com diabetes são proporcionar condições para o crescimento e o desenvolvimento normais associados à prevenção das complicações agudas e crônicas da doença. Esses objetivos são alcançados pela assistência coordenada por uma equipe multidisciplinar com foco em educação, plano alimentar, exercícios, administração de insulina, monitoração do tratamento, seguimento e prevenção das complicações crônicas. Novos análogos de insulina e métodos automatizados e programáveis de liberação de insulina, alguns destes implantáveis, têm revolucionado o tratamento do DMl. Esses novos métodos, além de melhorarem o controle da glicemia, procuram diminuir a variabilidade na liberação de insulina e os eventos hipoglicêmicos que continuam a ser obstáculos para se atingir um tratamento mais próximo do fisiológico no DMl. Quando esses métodos falham nesse sentido, os transplantes de pâncreas ou de ilhotas, cada um com seus critérios de inclusão, podem ser propostos. Essa é uma das áreas, associada ao desenvolvimento de novos imunossupressores com o objetivo de melhorar e aumentar a viabilidade e a função do enxerto em longo prazo, que tem evoluído rapidamente no tratamento do $\operatorname{DMl}(19)$.

No entanto, sabe-se que a restauração da homeostase metabólica no diabetes ainda é praticamente impossível. $\mathrm{O}$ resultado dessa insuficiência é a origem de um novo meio que inclui várias combinações de alterações metabólicas, hormonais e fisiológicas. Estas são a hiperinsulinemia, a hiperglicemia, a hiperlipidemia, as alterações no fluxo sanguíneo e na formação de produtos de glicação (20), que constituem o que denominamos exposição ao diabetes. Como conseqüência dessa exposição, várias alte- 
rações funcionais e morfológicas se desenvolvem levando às complicações micro e macroangiopáticas.

A proposta atual é de um tratamento multifatorial (de hiperglicemia, hipertensão arterial, dislipidemia, ao contrário de outros fatores de risco) para o DMl, do tratamento glicocêntrico do passado. Mais ainda, intensas pesquisas têm sido realizadas com o objetivo de detectarem-se quais desses componentes são os principais responsáveis por uma complicação em particular, com ênfase em marcadores genéticos determinados.

O DMlA, até o momento, não pode ser prevenido, mas estratégias com o objetivo de modular a resposta auto-imune, a ciência das células-tronco embrionárias, os processos de isolamento e proliferação das células progenitoras das células das ilhotas estão em evolução.

Esta edição fornece revisão e atualização dos maiores avanços na compreensão da etiologia, patogênese e do tratamento clínico e cirúrgico do DMl. Esses conhecimentos são apresentados e discutidos sobre a visão de especialistas nacionais e internacionais em suas áreas.

Como editores convidados, tivemos a satisfação de contar com a cooperação de todos os pesquisadores internacionais (Estados Unidos, Bélgica e França) e nacionais solicitados. Agradecemos a todos a oportunidade que nos deram de compartilhar seus dados e conceitos sobre essa complexa e heterogênea síndrome do DMl. Moléstia essa que os clínicos, endocrinologistas e pediatras estão entrando em contato com freqüência crescente.

Por fim, agradecemos à editora-chefe, Dra. Edna T. Kimura, e ao editor anterior, Dr. Cláudio E. Kater, dos ABE\&M, pelo apoio e pela liberdade para a realização deste projeto.

\section{REFERÊNCIAS}

1. American Diabetes Association. Diagnosis and classification of diabetes. Diabetes Care. 2008;31 (Suppl1):S55-S60.

2. Draper G, Dupurtius CW, Caughey JL. The differentiation by constitutional methods between pancreatic diabetes and diabetes of pituitary origin. Trans Assoc Am Phys. 1940;55:146-53.

3. Wrenshall GA, Bogoch A, Ritchie R. Extractable insulin of pancreas. Diabetes. 1952;1:87-107.
4. von Meyenburg H. Ueber "insulitis" bel diabetes. Schweiz Med Wochenschr. 1940;24:554-6.

5. Warren S. The pathology of diabetes in children. J Am Med Assoc. 1927;88:99-101.

6. Gepts W. Pathologic anatomy of the pancreas in juvenile diabetes mellitus. Diabetes. 1965;14:619-33.

7. Ungar B, Stocks AE, Martin FIR, Wittingham S, Mackay IR. Intrinsic-factor antibody in diabetes mellitus. Lancet. 1967; 2:77-8.

8. Irvine WJ, Clarke BF, Scarth L, Cullen D, Duncan LJP. Thyroid and gastric autoimmnunity in patients with diabetes mellitus. Lancet. 1970;2:163-8.

9. Nerup J, Bendixen G. Anti-adrenal cellular hypersensitivity in diabetes mellitus. Clin Exp Immunol. 1969;5:341-53.

10. Bottazzo GF, Florin-Christiansen A, Doniach LJP. Islet-cell antibodies in diabetes mellitus with autoimmune polyendocrine deficiencies. Lancet. 1974;2:1280-3.

11. Cudworth AG. The aetiology of diabetes mellitus. Br J Hosp Med. 1976;16:207-16.

12. Homman D, Eisenbarth GS. An immunologic homunculus for type 1 diabetes. J Clin Invest. 2006;116:1212-5.

13. Anonymous. EURODIAB ACE Study Group. Variation and trends in incidence of childhood diabetes in Europe. Lancet. 2000;355:873-6.

14. Onkano P, Vonnen S, Karvonen M, Tuomiletho J. Worldwide increase in incidence of Type 1 diabetes - the analysis of the data on published incidence trends. Diabetologia. 1999;339: 905-9.

15. Atkinson MA, Eisenbarth GS. Type 1 diabetes: new perpectives on disease pathogenesis and treatment. Lancet. 2001; 358:221-9.

16. Bach JF. The effect of infections on susceptibility to autoimmune and allergic diseases. N Engl J Med. 2002;347:911-20.

17. Libman IM, Becker DJ. Coexistence of type 1 and type 2 diabetes: "double" diabetes? Pediatr Diabetes. 2003;4:110-3.

18. Slingerland AS. Monogenic diabetes in children and young adults: Challenges for researcher, clinician and patient. Rev Endocr Disord. 2006;7:171-6.

19. Meloche RM. Transplantation for the treatment of type 1 diabetes. World J Gastroenterol. 2007;13:6347-55.

20. Brownlee M, Cerami A, Vlassara H. Advanced glycosilation end products in tissue and the biochemical basis of diabetic complications. N Engl J Med. 1988;318:1315-21.

Endereço para correspondência

Sergio Atala Dib

Disciplina de Endocrinologia

Rua Botucatu, 740

04023-900 - São Paulo, SP

E-mail: sergio.dib@unifesp.br 